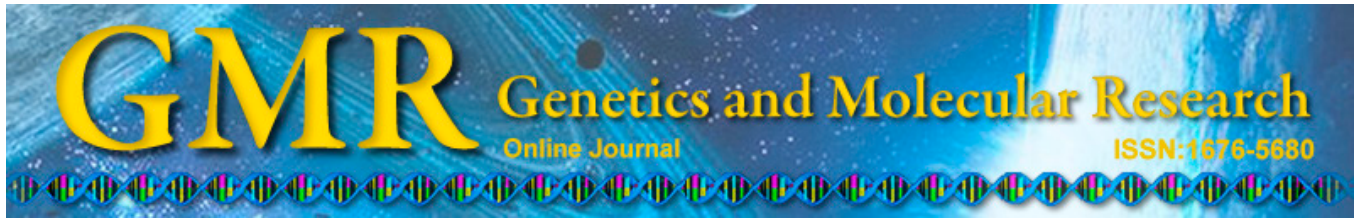

\title{
Development and characterization of microsatellite markers for the Chinese endangered medicinal plant Tetrastigma hemsleyanum
}

\author{
Y.H. Wang ${ }^{1,2}$, N. Chen ${ }^{1,2}$, Y.C. Zhang ${ }^{1}$ and C.X. Fu ${ }^{1,2}$ \\ ${ }^{1}$ Key Laboratory of Conservation Biology for Endangered Wildlife of the \\ Ministry of Education, College of Life Sciences, Zhejiang University, \\ Hangzhou, China \\ ${ }^{2}$ Laboratory of Systematic and Evolutionary Botany and Biodiversity, \\ Institute of Ecology, Conservation Center for Gene Resources of Endangered \\ Wildlife, Zhejiang University, Hangzhou, China \\ Corresponding author: C.X. Fu \\ E-mail: cxfu@zju.edu.cn
}

Genet. Mol. Res. 13 (4): 9062-9067 (2014)

Received October 21, 2013

Accepted August 10, 2014

Published October 31, 2014

DOI http://dx.doi.org/10.4238/2014.October.31.21

\begin{abstract}
Tetrastigma hemsleyanum (Vitaceae) is an endangered medicinal plant endemic to China. Because of its widely known efficacy for treating many health problems, wild resources of this species are currently undergoing a rapid decline. Few studies have been conducted examining the population genetics or development of microsatellite loci for this plant. In this study, 14 microsatellite loci were isolated and characterized for T. hemsleyanum using a doublesuppression PCR method. Polymorphisms were tested with a total of 50 individuals from 2 natural populations. The number of alleles per locus ranged from 3-9, with an average of 7 alleles per locus. The observed and expected heterozygosity per locus ranged from $0-1$ and from $0.068-0.803$, respectively. The polymorphism information content value varied from $0.215-0.760$. These loci may facilitate further genetic studies of populations of $T$. hemsleyanum and provide guidance for
\end{abstract}


their conservation.

Key words: Tetrastigma hemsleyanum; Microsatellites; Medicinal plant; Population genetics

\section{INTRODUCTION}

Tetrastigma hemsleyanum Diels et Gilg. (Vitaceae) is an herbaceous perennial plant endemic to China, distributed mainly south of the Chang Jiang (Yangtze). The entire plant, including the tubers, is reported to have anti-inflammatory, analgesic, antipyretic, and antiviral properties (Liu et al., 2002; Ding et al., 2005). Its functions in regulating the immune system, and potentially even tumor suppression, make it useful as an adjuvant medicine during cancer therapy, which has been confirmed in recent studies (Xu et al., 2008, 2009). Recently, overcollection of $T$. hemsleyanum due to its widely known efficacy, coupled with the loss of natural habitats, has reduced to the number of plants available for sustainable utilization, causing this plant to become an endangered species.

Assessment of population genetic variation in endangered medicinal plants is not only indispensable for efficient management and conservation, but also required for quality control in plants used for pharmaceutical purposes. Although the molecular phylogeny, chemical composition, pharmacology, and propagation techniques of T. hemsleyanum have been extensively studied (Xu et al., 2009; Chen et al., 2011; Jiang et al., 2011), the understanding of genetic variation in T. hemsleyanum is not well-understood because of the absence of efficient molecular markers. Simple sequence repeat (SSR) markers are present because of a high level of polymorphism and codominant inheritance (Wang et al., 2013); SSRs are among the most powerful tools for assessing the genetic structure and diversity of populations. In this study, we isolated and characterized polymorphic and monomorphic microsatellite markers from $T$. hemsleyanum to facilitate further genetic studies of populations.

\section{MATERIAL AND METHODS}

\section{Sample collection and DNA extraction}

Fifty wild T. hemsleyanum individuals were collected from Jinfo Mountain in Chongqing Municipality (JF) and Jianyang in Fujian Province (JY) of China. Fresh leaves from each plant were dried and preserved in silica gel for DNA extraction. Genomic DNA of T. hemsleyanum was extracted using Plantzol (Invitrogen, Carlsbad, CA, USA).

\section{Isolation of microsatellite markers}

A double-suppression PCR method (Lian et al., 2006) was used to construct a microsatellite-enriched library using 2 individuals from population JF. Briefly, total genomic DNA digested with a blunt-end restriction enzyme HaeIII (TaKaRa Biotechnology Co., Shiga, Japan) were ligated to unequal-length adaptors using the DNA Ligation Kit Version 2.0 (Takara). Next, compound SSR primer $(\mathrm{AC})_{6}(\mathrm{AG})_{5}$ or $(\mathrm{TC})_{6}(\mathrm{AC})_{5}$ and an adapter primer were used to amplify fragments flanked by a microsatellite at one end from the HaeIII DNA library as described by Ma et al. (2012). Amplified fragments between 400-1000 base pairs (bp) from the 
HaeIII DNA library were purified, ligated into a PMD19-T vector (Takara), and transformed into TOP10 competent cells (Tiangen Biotech, Beijing, China).

Among all cloned fragments, 672 clones were randomly chosen for analysis using M13 primers to amplify the entire microsatellite-containing insert. Polymerase chain reaction (PCR) was performed in a $10 \mu \mathrm{L}$ reaction mixture containing $1 \mu \mathrm{L}$ bacteria suspension, $1 \mu \mathrm{L} 10 \mathrm{X}$ PCR buffer with $\mathrm{MgCl}_{2}, 1 \mu \mathrm{L}$ dNTPs $(2.5 \mathrm{mM}$ each), and $0.5 \mu \mathrm{L}$ M13 primers for each $0.5 \mathrm{U}$ of Taq polymerase (Takara). PCR amplification conditions were as follows: initial denaturation at $95^{\circ} \mathrm{C}$ for $5 \mathrm{~min} ; 35$ cycles of $30 \mathrm{~s}$ at $95^{\circ} \mathrm{C}, 45 \mathrm{~s}$ at $56^{\circ} \mathrm{C}, 1.5 \mathrm{~min}$ of elongation at $72^{\circ} \mathrm{C} ; 10 \mathrm{~min}$ extension at $72^{\circ} \mathrm{C}$. A total of 157 positive clones obtained through PCR were sequenced on an ABI Prism 3730 automated DNA sequencer (Applied Biosystems, Foster City, CA, USA). One hundred and twenty-four sequences were found to contain $(\mathrm{AC})_{6}(\mathrm{AG})_{5}$ or $(\mathrm{TC})_{6}(\mathrm{AC})_{5}$ compound microsatellite motifs, among which 59 were removed because of insufficient flanking regions for primer design or high sequence homology. A total of 65 of the 124 sequences were suitable for designing primers and a specific primer (IP1) was designed using the PRIMER version 5.0 (Clarke and Gorley, 2001) flanking the compound SSR. However, the compound SSR primer can bind hundreds of sites across the entire genome, with the specificity of the primer pairs largely relying upon IP1. Therefore, we designed primer IP1 following the criteria: 1) primer size of 18-22 bp; 2) GC content within a range of $35-65 \%$; 3 ) melting temperature value difference in each primer pair less than $1.5^{\circ} \mathrm{C}$ to ensure amplification efficiency; 4) amplicon size between $80-350 \mathrm{bp}$. Finally, primer pairs with the highest score according to Primer Premier were selected for synthesis. An individually designed primer IP1 combined with a compound SSR primer constitute a compound SSR marker (Table 1).

Table 1. Characteristics of 14 compound microsatellite loci developed for Tetrastigma hemsleyanum.

\begin{tabular}{|c|c|c|c|c|c|}
\hline Locus (fluorescent dye) ${ }^{\mathrm{a}}$ & Repeat motif & Primer sequences $\left(5^{\prime}-3^{\prime}\right)$ & $\begin{array}{l}\text { Size range } \\
\text { (bp) }\end{array}$ & $\mathrm{Ta}\left({ }^{\circ} \mathrm{C}\right)$ & $\begin{array}{c}\text { GenBank } \\
\text { accession No }\end{array}$ \\
\hline Tehe158(HEX) & $(\mathrm{TC})_{6}(\mathrm{AC})_{5}$ & $\begin{array}{l}\text { F: TCTCTCTCTCTCACACACACAC } \\
\text { R: GGCACTGGCACATTATTT }\end{array}$ & $144-172$ & 58 & KF557580 \\
\hline Tehe220(HEX) & $(\mathrm{AC})_{6}(\mathrm{AG})_{6}$ & $\begin{array}{l}\text { F: ACACACACACACAGAGAGAGAG } \\
\text { R: ATGAATAAGCCCAGACTACAC }\end{array}$ & 293-307 & 60 & KF557577 \\
\hline Tehe272(FAM) & $(\mathrm{AC})_{6}(\mathrm{AG})_{5}$ & $\begin{array}{l}\text { F: ACACACACACACAGAGAGAGAG } \\
\text { R: GGAGGACCTGTTATTTGGA }\end{array}$ & $316-330$ & 58 & KF557575 \\
\hline Tehe17(FAM) & $(\mathrm{TC})_{6}(\mathrm{AC})_{5}$ & $\begin{array}{l}\text { F: TCTCTCTCTCTCACACACACAC } \\
\text { R: ATCATCCAACCAGACCCT }\end{array}$ & $274-278$ & 61 & KF557579 \\
\hline Tehe135(HEX) & $(\mathrm{TC})_{6}(\mathrm{AC})_{5} \mathrm{CCA}(\mathrm{CT})_{7}$ & $\begin{array}{l}\text { F: TCTCTCTCTCTCACACACACAC } \\
\text { R: ATCACAGACGCATAAGGG }\end{array}$ & $219-235$ & 61 & KF557582 \\
\hline Tehe153(FAM) & $(\mathrm{TC})_{6}(\mathrm{AC})_{7}$ & $\begin{array}{l}\text { F: TCTCTCTCTCTCACACACACAC } \\
\text { R: GAGCCGTCTAAGAATAAGTTG }\end{array}$ & $138-158$ & 58 & KF557581 \\
\hline Tehe44(FAM) & $(\mathrm{AC})_{6}(\mathrm{AG})_{8}$ & $\begin{array}{l}\text { F: ACACACACACACAGAGAGAGAG } \\
\text { R: TACAGTCACCACGGCAAT }\end{array}$ & $256-276$ & 57.5 & KF557574 \\
\hline Tehe10(HEX) & $(\mathrm{TC})_{6}(\mathrm{AC})_{5}$ & $\begin{array}{l}\text { F: TCTCTCTCTCTCACACACACAC } \\
\text { R: CTTCTCAATGGCATCCTG }\end{array}$ & $110-128$ & 60 & KF557583 \\
\hline Tehe234(HEX) & $(\mathrm{TC})_{6}(\mathrm{AC})_{9}$ & $\begin{array}{l}\text { F: TCTCTCTCTCTCACACACACAC } \\
\text { R: AGCAGAAAAGGCTGGAAA }\end{array}$ & $114-136$ & 59 & KF557576 \\
\hline Tehe187(HEX) & $(\mathrm{TC})_{6}(\mathrm{AC})_{10}$ & $\begin{array}{l}\text { F: TCTCTCTCTCTCACACACACAC } \\
\text { R: CTCTGGTGAGGAGGTTGG }\end{array}$ & $116-130$ & 61 & KF557578 \\
\hline Tehe166(FAM)* & $(\mathrm{TC})_{6}(\mathrm{AC})_{5}$ & $\begin{array}{l}\text { F: TCTCTCTCTCTCACACACACAC } \\
\text { R: GCCCAAAGTCATCAATCA }\end{array}$ & 185 & 56 & KF595083 \\
\hline Tehe82(HEX)* & $(\mathrm{AC})_{6}(\mathrm{AG})_{5} \mathrm{AA}(\mathrm{AG})_{3}$ & $\begin{array}{l}\text { F: ACACACACACACAGAGAGAGAG } \\
\text { R: CTAAGGGCATGGACAAGA }\end{array}$ & 100 & 55 & KF595080 \\
\hline Tehe63(FAM)* & $(\mathrm{AC})_{6}(\mathrm{AG})_{5}$ & $\begin{array}{l}\text { F: ACACACACACACAGAGAGAGAG } \\
\text { R: AGTAGAAGACCGTATGATTAGC }\end{array}$ & 92 & 55 & KF595081 \\
\hline Tehe5(FAM)* & $(\mathrm{AC})_{6}(\mathrm{AG})_{5}$ & $\begin{array}{l}\text { F: ACACACACACACAGAGAGAGAG } \\
\text { R: GGTCATTGCCTGTGCTAA }\end{array}$ & 281 & 58 & KF595082 \\
\hline
\end{tabular}

$\mathrm{Ta}=$ annealing temperature. ${ }^{\mathrm{a}}$ Monomorphic loci are marked with an asterisk $\left({ }^{*}\right)$. 
All PCR reactions were performed in a $10 \mu \mathrm{L}$ reaction mixture containing $50 \mathrm{ng}$ template DNA, $1.5 \mu \mathrm{L}$ 10X PCR buffer containing $\mathrm{MgCl}_{2}, 0.8 \mu \mathrm{L}$ dNTPs $(2.5 \mathrm{mM}), 0.5 \mu \mathrm{L}$ each primer $(10 \mu \mathrm{M}), 0.75 \mathrm{U} \mathrm{Taq}$ polymerase (Takara) and $0.1 \mu \mathrm{L}$ bovine serum albumin (BSA) (Takara). PCR amplification conditions were as follows: initial denaturation at $94^{\circ} \mathrm{C}$ for 5 min; 35 cycles of $30 \mathrm{~s}$ of denaturation at $94^{\circ} \mathrm{C}, 45 \mathrm{~s}$ of annealing at the optimized annealing temperature (Table 1), $30 \mathrm{~s}$ of elongation at $72^{\circ} \mathrm{C}$; final extension at $72^{\circ} \mathrm{C}$ for $10 \mathrm{~min}$. To assess amplification efficiency, PCR products, along with a DL2000 DNA ladder (Takara), were electrophoresed on $2.0 \%$ agarose gels and stained with ethidium bromide. Primers that produced either no band or multiple bands were rejected. Other primer pairs producing amplicons matched with the expected sizes were eventually chosen to further test for polymorphisms using JF and JY populations. We verified the reproducibility of these amplicons by repeating the experiments. Compound primers for each pair were labeled with a fluorescent dye (6-FAM, or HEX). PCR amplifications were performed as described above. Equal volumes of PCR products that had been diluted 10X were amplified using 2 different dye-labeled primers mixed with GS500 size standards. Fragment analysis was performed on a MegaBACE 1000 autosequencer (GE Healthcare, Little Chalfont, UK). Alleles were visualized and scored manually using the GeneMaker version 2.20 (SoftGenetics, State College, PA, USA).

\section{Data analysis}

Marker polymorphisms, including the number of observed alleles per locus $\left(N_{\mathrm{A}}\right)$, observed $\left(H_{\mathrm{O}}\right)$ and expected $\left(H_{\mathrm{E}}\right)$ heterozygosities, and polymorphic information content (PIC) were calculated using the CERVUS version 3.0.3 (Kalinowski et al., 2007). Deviation from Hardy-Weinberg equilibrium (HWE) and linkage disequilibrium were determined using the GENEPOP version 4.0.10 (Rousset, 2008). Sequential Bonferroni procedures were implemented to adjust for significance levels of multiple tests (Rice, 1989). The existence of null alleles, allelic dropout, and scoring errors (due to stuttering) were tested using the MICROCHECKER version 2.2.3 (Van Oosterhout et al., 2004).

\section{RESULTS AND DISCUSSION}

Fifty-nine primers were designed from sequences isolated from microsatellite-enriched libraries. After rejecting primers that either produced no band or multiple bands, 14 primer pairs were identified to yield one clear band, indicating that each marker amplified a locus-specific microsatellite region. After further testing for polymorphisms, 10 of 14 primer pairs were confirmed to be polymorphic. However, the other 4 monomorphic pairs were also included because of their potential use in other populations or related species.

All 10 polymorphic markers (Table 1) showed mean allelic richness of 4.1 (range: 2-7) and 4.7 (range: 2-7) for JF and JY populations (Table 2). The average observed heterozygosity within each population was 0.393 (range: $0.000-0.786$ ) and 0.5483 (range: $0.000-1.000$ ), expected heterozygosity averaged 0.550 (range: $0.254-0.762$ ) and 0.5416 (range: $0.068-0.803$ ), respectively (Table 2), and PICs were 0.478 (range: 0.215-0.692) and 0.487 (range: 0.0640.760 ), respectively (Table 2 ). Therefore, degree of genetic diversity among the 2 screened JF and JY populations showed no significant differences. Locus Tehe234 and Tehe187 were considered to be more polymorphic when compared with other microsatellite loci in Table 2. 
Table 2. Summary statistics of SSR marker polymorphism screened in 2 populations of Tetrastigma hemsleyanum.

\begin{tabular}{|c|c|c|c|c|c|c|c|c|c|c|c|}
\hline \multirow[b]{2}{*}{ Locus } & \multicolumn{5}{|c|}{ Population JF $(\mathrm{N}=14)^{\mathrm{a}}$} & \multirow[t]{2}{*}{$\mathrm{A}$} & \multicolumn{5}{|c|}{ Population JY $(\mathrm{N}=29)^{\mathrm{a}}$} \\
\hline & $N_{\mathrm{A}}$ & $H_{\mathrm{O}}$ & $H_{\mathrm{E}}$ & PIC & $\mathrm{HWE}^{\mathrm{b}}$ & & $N_{\mathrm{A}}$ & $H_{\mathrm{O}}$ & $H_{\mathrm{E}}$ & PIC & $\mathrm{HWE}^{\mathrm{b}}$ \\
\hline Tehe158 & 4 & 0.286 & 0.553 & 0.487 & $0.0289 *$ & 5 & 3 & 0.517 & 0.485 & 0.411 & $0.6639^{\text {n.s. }}$ \\
\hline Tehe220 & 4 & 0.714 & 0.616 & 0.510 & $0.0196^{*}$ & 7 & 5 & 1.000 & 0.657 & 0.579 & $0 * * *$ \\
\hline Tehe272 & 2 & 0.286 & 0.254 & 0.215 & $1.0000^{\text {n.s. }}$ & 6 & 6 & 0.897 & 0.587 & 0.489 & $0 * * *$ \\
\hline Tehe17 & 2 & 0.000 & 0.349 & 0.280 & $0.0007 * * *$ & 3 & 2 & 0.000 & 0.068 & 0.064 & $0.0170 *$ \\
\hline Tehe135 & 4 & 0.214 & 0.373 & 0.331 & $0.0754^{\text {n.s. }}$ & 5 & 3 & 0.069 & 0.068 & 0.066 & $1.0000^{\text {n.s. }}$ \\
\hline Tehe153 & 7 & 0.286 & 0.582 & 0.540 & $0.0007 * * *$ & 9 & 7 & 0.379 & 0.621 & 0.577 & $0 * * *$ \\
\hline Tehe44 & 5 & 0.071 & 0.738 & 0.667 & $0 * * *$ & 8 & 5 & 0.414 & 0.711 & 0.644 & $0.009 * *$ \\
\hline Tehe10 & 2 & 0.500 & 0.516 & 0.374 & $1.0000^{\text {n.s. }}$ & 5 & 5 & 0.552 & 0.674 & 0.599 & $0.2874^{\text {n.s. }}$ \\
\hline Tehe234 & 6 & 0.786 & 0.757 & 0.686 & $0.3930^{\text {n.s. }}$ & 9 & 5 & 0.724 & 0.742 & 0.686 & $0.0002 * *$ \\
\hline Tehe187 & 5 & 0.786 & 0.762 & 0.692 & $0.1086^{\text {n.s. }}$ & 9 & 6 & 0.931 & 0.803 & 0.760 & $0.0002 * *$ \\
\hline
\end{tabular}

$\mathrm{A}=$ number of alleles per locus across both populations; $N_{\mathrm{A}}=$ number of alleles per locus; $H_{\mathrm{O}}=$ observed heterozygosity (mean value); $H_{\mathrm{F}}=$ expected heterozygosity (mean value); $\mathrm{PIC}=$ polymorphism information content; HWE = Hardy-Weinberg equilibrium; n.s. = not significant; the sample size for each population is indicated in parentheses. ${ }^{\mathrm{a}}$ Locality information: JF $=$ Jinfo Mountain, Chongqing Municipality; JY = Jianyang, Fujian Province.



Hardy-Weinberg equilibrium (HWE) was detected for each locus, and 4 loci (Tehe158, Tehe17, Tehe153, Tehe44) showed significant deviation from HWE $(\mathrm{P}<0.05)$ in both populations (Table 2). The results of the null alleles test showed were very similar to the HWE test results. Specifically, 4 loci (Tehe158, Tehe17, Tehe153, Tehe44) in JF population and 3 loci (Tehe17, Tehe153, Tehe44) in JY population showed the possible presence of null alleles according to MICRO-CHECKER. Departures from HWE, most of which were caused by heterozygote deficiency, may have been caused by the presence of null alleles. Although other factors such as inbreeding, the Wahlund effect, and selection can also result in heterozygote deficiency, the general main cause is the existence of non-amplifying PCR null alleles (Selkoe and Toonen, 2006), as heterozygotes are easier to be scored as homozygotes. Null alleles are generally the prior concerned factor, particularly when deviation from HWE occurs exclusively in specific loci (Panova et al., 2008). No significant linkage disequilibrium was found between any pair of loci across the 2 wild populations.

In conclusion, 14 nuclear microsatellite markers, including 4 monomorphic and 10 polymorphic markers, were developed for Tetrastigma hemsleyanum. Alleles of the 10 polymorphic loci were subject to changes in the number of SSR motifs and were verified to be reliable and repeatable. Primers presented here are adequate for detecting and characterizing population genetic structure and genetic diversity in T. hemsleyanum. Therefore, these markers will allow inferences to be made regarding population history and will provide guidance for establishing conservation strategies.

\section{ACKNOWLEDGMENTS}

The authors thank David E. Boufford and L. Zheng for technical support during experiments and for their suggestions on manuscript preparation. Research supported by the Zhejiang Provincial Natural Science Foundation (\#LY14C0220002), the Key Breeding Project of Zhejiang Province (\#2012C12912) and the National Natural Science Foundation of China (\#30830011). 


\section{REFERENCES}

Chen P, Chen L and Wen J (2011). The first phylogenetic analysis of Tetrastigma (Miq.) Planch., the host of Rafflesiaceae. Taxon 60: 499-512.

Clarke KR and Gorley RN (2001). Primer v5: User Manual/Tutorial. Primer-E Ltd., Plymouth, UK.

Ding GQ, Zheng JX, Wei KM and Pu JB (2005). Toxicological effects of the extract of Tetrastigma hemsleyanum Diels et. Gilg on hepatocellular carcinoma cell line HepG2 and primary rat hepatocytes in vitro. Zhejiang Prev. Med. 17: 1-5.

Jiang WM, Fu YM, Zhou XL and Fu CX (2011). High-frequency shoot regeneration of nodal explants from Tetrastigma hemsleyanum Diels et. Gilg: A valuable medicinal plant. Afr. J. Biotechnol. 10: 12177-12181.

Kalinowski ST, Taper ML and Marshall TC (2007). Revising how the computer program cervus accommodates genotyping error increases success in paternity assignment. Mol. Ecol. 16: 1099-1106.

Lian CL, Abdul WM, Geng Q, Shimatani K, et al. (2006). An improved technique for isolating codominant compound microsatellite markers. J. Plant Res. 119: 415-417.

Liu D, Ju JH, Lin G, Xu XD, et al. (2002). New C-glycosylflavones from Tetrastigma hemsleyanum (Vitaceae). Acta. Bot. Sin. 44: 227-229.

Ma WW, Zhai SN, Zhang YH and Qiu YX (2012). Development and characterization of microsatellite markers for Emmenopterys henryi (Rubiaceae), a rare tree from China. Am. J. Bot. 99: e179-e181.

Panova M, Mäkinen T, Fokin M, André C, et al. (2008). Microsatellite cross-species amplification in the genus Littorina and detection of null alleles in Littorina saxatilis. J. Mollus. Stud. 74: 111-117.

Rice WR (1989). Analyzing tables of statistical tests. Evolution 43: 223-225.

Rousset F (2008). Genepop'007: a complete re-implementation of the genepop software for Windows and Linux. Mol. Ecol. Resour. 8: 103-106.

Selkoe KA and Toonen RJ (2006). Microsatellites for ecologists: a practical guide to using and evaluating microsatellite markers. Ecol. Lett. 9: 615-629.

Van Oosterhout C, Hutchinson WF, Wills DP and Shipley P (2004). Micro-checker: software for identifying and correcting genotyping errors in microsatellite data. Mol. Ecol. Notes 4: 535-538.

Wang A, Wujisguleng W, Liu YJ, Liu Y, et al. (2013). Isolation and characterization of polymorphic microsatellite loci for the valuable medicinal plant Astragalus mongholicus. Open J. Genet. 3: 89-92.

Xu CJ, Bai NN, Meng J, Fu JY, et al. (2009). A study on effect of anti-tumor of extract from Tetrastigma hemsleyanum Diels et. Gilg and its mechanisms in vivo. Chin. J. Health. Lab. Technol. 2: 278-280.

Xu CJ, Ding GQ, Fu JY, Meng J, et al. (2008). Immunoregulatory effects of ethyl-acetate fraction of extracts from Tetrastigma hemsleyanum Diels et. Gilg on immune functions of ICR mice. Biomed. Environ. Sci. 21: 325-331. 